\title{
The Effect of Raised Walkway Design on Evacuation Behaviour in Rail Tunnels
}

\author{
FRIDA VERMINA LUNDSTRÖM ${ }^{1}$, JENNY AHLFONT ${ }^{2}$, and DANIEL NILSSON ${ }^{2}$ \\ ${ }^{1} \mathrm{DBI}$ - Danish Institute of Fire and Security Technology \\ Jernholmen 12 \\ DK- 2650 Hvidovre, Denmark \\ ${ }^{2}$ Department of Fire Safety Engineering \\ Lund University \\ Box 118
}

SE-221 00 Lund, Sweden

\begin{abstract}
The use of raised walkways in rail tunnels has the potential to significantly improve evacuation conditions, however there is limited research that has so far focused on walkway design from an evacuation perspective. An experiment was therefore performed to explore the effect of walkway design, namely walkway width and evacuation aids, on evacuation behaviour, e.g., people's perception, movement speeds and flow rate. The results indicate that a walkway width of more than approximately one metre $(0.9$ to 1.05 $\mathrm{m}$ ) leads to higher movement speeds and increased sense of safety. Handrails and a tactile edge marker are often appreciated evacuation aids as they are perceived as facilitating and safety-enhancing features. Based on the results, a correlation between flow rate and walkway width has been developed. This correlation and the collected data may potentially be used in future cost-benefit analyses to shed light on the most appropriate walkway design for specific tunnels.
\end{abstract}

KEYWORDS: underground rail transportation system, experiment, walkway, human behaviour, evacuation, rail tunnels

\section{INTRODUCTION}

Fires in underground rail transportation systems, e.g., tunnels and underground stations, can have devastating consequences. Examples include the fire in the Kaprun tunnel that killed 155 people [1,2], the King's Cross fire that killed 31 people [3], and the Baku Metro fire where 289 people lost their lives [4]. The severity of tunnel fires is often related to the enclosed nature of the tunnel environment, but the complexity of evacuation is also a contributing factor. Part of the complexity is related to the fact that people often encounter obstacles on their way from the train to a safe location [5]. One example of an obstacle is the evacuation from the train down to track level, which can be difficult (or even impossible) for children, senior citizens and people with movement disabilities.

In most rail tunnels, the general principle is that the train will continue out from the tunnel or go to the nearest station in the case of a fire [6]. However, past accidents have shown that trains do, in fact, stop inside tunnels for different reasons in emergencies. One example is the Baku Metro fire where an electrical failure in the train resulted in a fire and made the train stop between two metro stations [4]. Another example is the fire in the Hirschengraben Tunnel in Zürich where the train also was stopped inside the tunnel [7]. In these types of situations, people will be forced to evacuate from the train in an inhospitable tunnel environment, which may involve negotiating a relatively high vertical drop from the train down to track level. As an example, it can be mentioned that the vertical distance between the train floor and the track level in the Stockholm Metro is 1.4 meters [8].

If a train stops in a tunnel, it may be difficult (or even impossible) for some evacuees to get out from the train. Experiments by Oswald, Kirchberger, and Lebeda [9] have shown that people who are relatively fit often manage to evacuate from train down to track level and that they use different exiting strategies. However, for people with movement disabilities it may be impossible to overcome a vertical height difference [8]. One way that may help facilitate safe evacuation is to install raised walkways in tunnels. These walkways, which can be placed on one or both sides of the tunnel, make evacuation from the train easier as the vertical height difference is removed (or reduced). This design feature is often implemented in new rail tunnels, such as the City Tunnel in Malmö or the Metro in Copenhagen [10]. 
Raised walkways in tunnels may improve the evacuation conditions, but some questions about the design of walkways still remain unanswered. According to Swedish regulations, the luminance should not be below 1 lux in rail tunnel [11]. This luminance level may be perceived as relatively dark, which can complicate evacuation via raised walkways. For example, people may be afraid of falling down onto the railway tracks. One way to improve this situation could be to install evacuation aids of which examples may include handrails along the tunnel wall or tactile ground surface indicators along the edge of the walkway. These types of systems can potentially make people feel safer and enable them to move faster.

The width of walkways in existing tunnels varies. However, there is limited research that has focused on the influence of the width on people's evacuation behaviour. According to EU regulations, walkways in tunnels should be at least 0.75 metres wide in most tunnels. However for long tunnels $(>20 \mathrm{~km})$ the minimum width requirement is 1.2 metres [12]. The width of walkways in existing tunnels often lies around these required values, examples include; the Copenhagen Metro (width 0.7 metres) and the City Tunnel in Malmö (width 1.2 metres) [10]. An interesting question is how the width of these walkways influences evacuation behaviour? A wider walkway will presumably lead to faster movement speed and also higher flow rates. Specifically, people may move slowly on very narrow walkways. Therefore, wider walkways will most likely improve evacuation conditions. However, this will also lead to increased cost for the infrastructure project by requiring a wider tunnel cross section. A cost-benefit analysis may shed light on the most appropriate walkway width for a specific tunnel, however this type of analysis requires data on the effect of the width on such aspects as movement speed and flow rate.

Walkways are often built in new rail tunnels to avoid the difficulties of evacuation from train to track level. Few studies have, however, examined the design of these raised walkways in tunnels. How does, for example, the width of the walkway influence the evacuation behaviour, e.g., the movement speed and flow rate? Also, can evacuation aids help people to feel safer and make it possible for them to move faster? These questions are imperative to address as walkways are being built in many new tunnels.

In 2012, laboratory experiments were performed at Lund University in order to study the influence of walkway design on evacuation behaviour in rail tunnels [13]. The objective of the study is to:

(i) quantify the effect of walkway width on movement speed and flow rate,

(ii) find out how people perceive evacuation via walkways in relation to important factors, such as the width and height of the walkway, and

(iii) obtain information about the effect of evacuation aids, namely handrails and tactile edge markers (tactile ground surface indicator), on people's behaviour during evacuation via walkways.

The goal of the study is to provide new empirical data on human behaviour during evacuation via raised walkways in rail tunnels. Furthermore, this new data should be presented in a way that enables its use in future cost-benefit analyses of walkway design.

\section{METHOD}

An experiment was performed on the $30^{\text {th }}$ of August and the $3^{\text {rd }}$ of September 2012 at Lund University, Sweden. A model of a tunnel walkway was used in order to study the effects of walkway width on evacuation behaviour. The experiment was divided into two parts. The first part of the experiment sought to investigate the significance of the walkway width on the evacuation, and the second part investigated the role that evacuation aids play. The subsequent sections include a description of the participants, the model of a raised walkway, the instruments, and the procedure of the experiment.

\section{Participants}

The participants mainly consisted of new students at the Fire Protection Engineering Program at Lund University, and a small percentage of participants were employees or students at the Master of Science Program in Risk Management and Safety Engineering. The experiment took place during orientation week, which is the students' first week at the University. Thus, the majority of the participants did not have any significant experience in evacuation experiments.

A total of 48 people, 31 men (65\%) and 17 women (35\%), participated in the first part of the experiment (test of various widths). The age of the participants ranged between 18 and 27 years, with an average of 21 
years. The second part of the experiment (test of evacuation aids) involved 24 participants, 17 men (81\%) and 4 women (19\%). The age of the participants ranged between 18 and 30 years with an average of 23 years. The participants received no reimbursement except for snacks and coffee.

\section{Model of a raised walkway}

The evacuation experiment was performed in the laboratory hall of the V-building at Lund University. A platform measuring 18 meters long, 2.3 meters wide and 1.3 meters high was constructed, i.e., a raised walkway, refer Fig. 1. A movable wall was placed on the side platform thereby allowing the width of the walkway to be changed. The height of the walkway was chosen to represent the height in the Stockholm Metro [8]. The various widths used in the experiment are commented in Table 1.

Table 1 . The different walkway widths used in the experiment $[11,12]$.

\begin{tabular}{ll}
\hline Width $[\mathrm{m}]$ & Comment \\
\hline 0.60 & - \\
0.75 & The width according to the EU regulations. \\
0.85 & The width according to the EU regulations, including space for a handrail. \\
0.90 & $\begin{array}{l}\text { The width according to Swedish regulations, for railway tunnels with the length of } \\
100-500 \mathrm{~m} .\end{array}$ \\
1.05 & - \\
1.20 & The width according to Swedish and EU regulations, for railway tunnels with the \\
& length of more than $500 \mathrm{~m}$ or $20 \mathrm{~km}$, respectively. \\
\hline
\end{tabular}

(a)

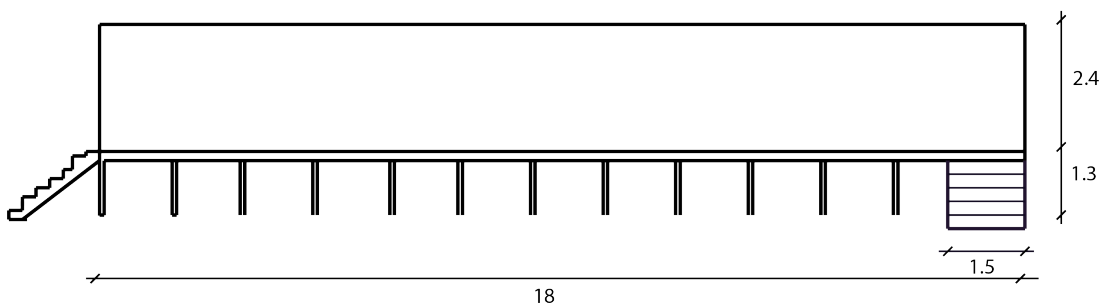

(c)

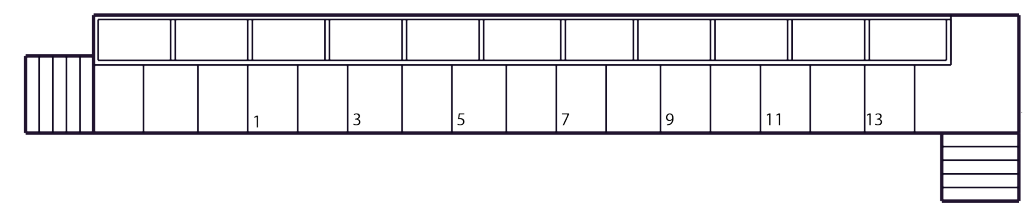

(b)

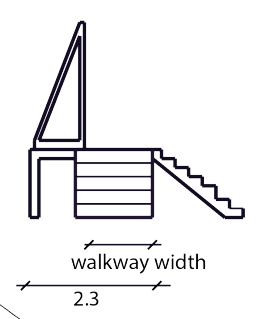

(d)

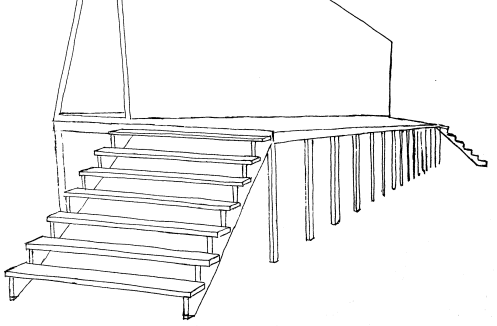

Fig. 1. The model of a raised walkway; (a) Side view, (b) Front view, (c) Top view with markings every meter, (d) Perspective view.

Stairs were constructed at both ends of the platform to allow participants to enter and exit at either end of the walkway. The stairs were 1.5 metres wide. This width was chosen to ensure that stair width would not restrict the flow.

Tunnel lighting was mounted at the movable wall. It consisted of two light fixtures with flouresent lamps placed eight metres apart. These produced an intensity level of 1 lux inbetween the lamps, which is the 
minimum lighting required by the Swedish regulations [11]. The lamps were located one metre above the walkway. These distances and light intensity resemble the lighting conditions in the Stockholm Metro [8].

In the second part of the experiment (test of evacuation aids), a handrail attached to the wall was installed at a height of 1 metre above the walkway. The handrail was comprised of a round rod with associated attachment devices, see Fig. 2. A tactile edge marker was also placed at the outer side of the walkway, see Fig. 2. This consisted of a diagonally sawed board, i.e., a wedge.

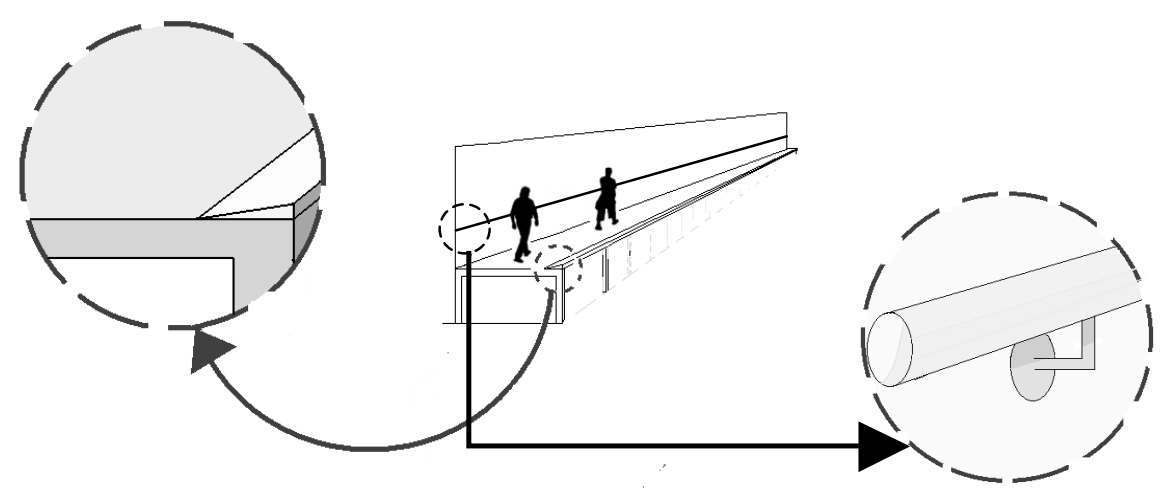

Fig. 2. Illustration of the tactile edge marker and the handrail

\section{Instruments}

Evacuation behavior data was collected by using measuring devices such as video cameras. Questionnaires were also used in order to capture the experiences that the participants had with the different walkway designs.

\section{Measuring devices}

In order to measure the movement of participants on the walkway, the experiment was recorded by seven video cameras placed in a linear array, see Fig. 3. Each camera was located three metres above the walkway with the lens facing downward in order to film participants from above. IR illumination was used in the first part of the experiment (test of various widths) in which there was a low luminance. The IR light could not be seen by the participants, but made it possible to record their movement despite the low illumination.

The walkway was divided into 18 one metre sections by markings. These markings were then used to calculate evacuation behaviour, i. e. movement speed, flow rate and density. Every other line was also marked with a number.

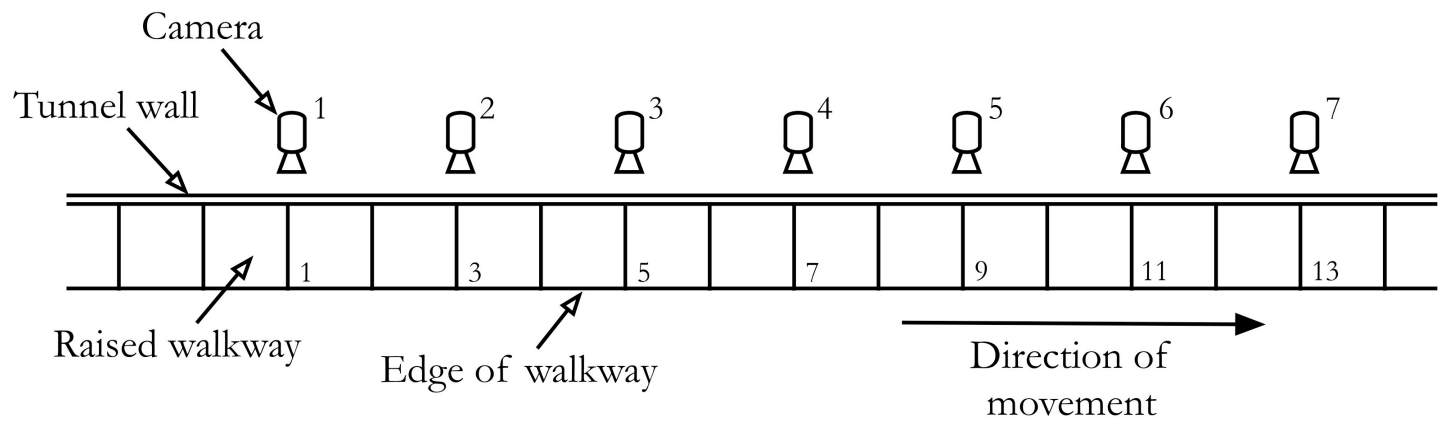

Fig. 3. Schematic drawing of camera locations and markers on the walkway. 
The incident light on the walkway was measured at seven different locations with a luxmeter. The first part of the experiment (test of various widths) was conducted at night, while the second part (test of evacuation aids) was performed at midday. Incident light from the windows was not mitigated; however the lights in the laboratory hall were turned off. The light intensity varied between 0.2 and 29.8 lux in the first part of the experiment, with an average level of 6.2 lux. In the second part, the intensity level varied between 960 and 2100 lux, with an average of 1250 lux.

\section{Questionnaires}

After each walkway width, participants completed a questionnaire, which included multiple-choice statements about their experiences of the walkway. The statements were presented in mutually-exclusive pairs, see Table 2. This design intended to capture any inconsistency in the participants' answers. The response options for the multiple-choice statements were ranged by a four-graded Likert scale in order to capture a range of senses that the participants experienced regarding the width and height of the walkway. A Likert scale is applied when discrete values are not considered to be sufficient [14]. The response options given were; Strongly Agree, Agree, Disagree and Strongly Disagree.

Table 2. Questionnaire Statements.

\begin{tabular}{ll}
\hline Conditional Statement & Negation Statement \\
\hline I felt unsafe since I considered the walkway to be & $\begin{array}{l}\text { I considered the walkway to be fully sufficient to } \\
\text { walk on. }\end{array}$ \\
$\begin{array}{ll}\text { narrow. } \\
\text { The width of the platform led me to walk more } \\
\text { cautious than usual. }\end{array}$ \\
$\begin{array}{l}\text { The width of the walkway did not affect my } \\
\text { walking speed }\end{array}$ \\
$\begin{array}{ll}\text { I considered the height of the walkway to be very } \\
\text { Ihe height of the walkway led me to walk more } \\
\text { cautious than usual. }\end{array}$ & $\begin{array}{l}\text { affected me significantly. } \\
\text { The height of the walkway did not affect my } \\
\text { movements. }\end{array}$ \\
\hline
\end{tabular}

In the second part of the experiment (test of evacuation aids), two open-ended questions about the evacuation aids were added. The first question was related to the difference in experience with and without handrails. The second question investigated how the experience differed between the situations with and without the tactile edge marker.

\section{Experimental Procedure}

The two parts of the experiment were divided into a total of nine scenarios, see Table 3. The first six scenarios (Scenario 1 to 6 ) sought to quantify the effect that the width of the walkway has on evacuation behaviour, as well as how the participants perceived the evacuation. The last three scenarios (Scenario 7 to 9) investigated the role that evacuation aids play.

Table 3. Scenarios.

\begin{tabular}{lllll}
\hline Part & Scenario & Walkway Width [m] & Evacuation Aids & Number of Runs \\
\hline 1 & 1 & 0.60 & None & 3 \\
1 & 2 & 0.75 & None & 5 \\
1 & 3 & 0.90 & None & 5 \\
1 & 4 & 1.05 & None & 5 \\
1 & 5 & 1.20 & None & 5 \\
1 & 6 & 1.35 & None & 5 \\
\hdashline 2 & 7 & 0.80 & Handrail, tactile edge marker & 5 \\
2 & 8 & 0.80 & Tactile edge marker & 5 \\
2 & 9 & 0.80 & None & 5 \\
\hline
\end{tabular}


When all participants had assembled at the location of the experiment, they were thoroughly informed about the experiment and the risks. The participants were not, however, in detail informed about the objectives of the experiment. In addition, they were informed of their rights, according to the Swedish ethics act [15]. They were asked to walk at normal speed and to use the full width of each set of stairs. No smoke or fire was simulated. During the experiments, the participants did not wear any coats or carry any luggage.

Each scenario started with a gathering of participants on the steps up to the walkway. The participants were then instructed to maintain a high density up the stairs, but to then continue onto the walkway at a normal pace. Once they completed the first round they were instructed to once again gather at the starting point to walk on the walkway again. The procedure was repeated 5 times for each width. This enabled the collection of more data for measuring evacuation behaviour for each scenario. The walkway widths were increased in each scenario instead of varying the width between narrower and wider widths. This was due to the safety considerations derived from a what if-analysis, see the section on ethical considerations.

\section{Analysis of data}

The video recordings were used to determine the evacuation behavior, i.e. movement speed, flow rate and density. Walking speed was measured by examining the time it took for each person to walk the distance of 10 metres between camera 2 and 7, refer Fig. 3. Dynamic flow rate was determined as the number of participants divided by the time it took for all the participants to pass a specific point on the walkway, refer Eq. 1 [16]. The specific flow was calculated, using the effective width $W_{e}$, i.e. the part of the walkway that was actually used by the participants, refer Eq. 2. The specific flow is calculated with a $20 \mathrm{~cm}$ narrower width than the actual width [16]. Instantaneous density was calculated as a function of the number of people on the walkway at a specific time step (i) divided by the area of the walkway, refer Eq. 3 [17]. The average density for each scenario was then calculated by dividing the sum of all instantaneous density measurements with the number of measurements, refer Eq. 4. Measurements of instantaneous density were made once for every run (i.e. 5 times per width).

$$
\begin{aligned}
& F=\frac{N}{\Delta t} \\
& F_{S}=\frac{N}{W \cdot \Delta t} \\
& \rho_{i}=\frac{N_{i}}{W \cdot \Delta x} \\
& \rho_{\text {average }}=\frac{\sum \rho_{i}}{i}
\end{aligned}
$$

The data collected in the experiment was analyzed using the statistical software Minitab. Differences in movement speed in scenarios 1-6 were analyzed with a post hoc test according to Tukey [18]. A regression analysis was performed on the results of the dynamic flow rate in order to identify how well the experimental data plot fitted with the regression line extrapolated from the plot. The answers in the questionnaire, referring to the participants' subjective experience of the walkways width and the impact this had, were studied qualitatively. An assumption was made of equal distances between each response option.

\section{RESULTS}

The results are presented in the following sections, where the first section contains results derived from Scenarios 1 to 6 and the latter section presents the results from Scenarios 7 to 9 .

\section{Part 1 - Test of various Walkway Widths}

The relationship between movement speed and walkway width is illustrated in Fig. 4 (a). Each dot in the diagram shows the median velocity and the bottom and top bar show the 5th and 95th percentiles respectively. The mean values and standard deviations are presented in Table 4. A one way ANOVA was performed, examining if the movement velocity changed between each scenario. The result revealed that at least one of the average velocities differ from the others, $F(5.582)=112.2, p<.001$. A post hoc test, using 
Tukey's HSD criterion, indicates that the average velocities was significantly higher for the widths $1.05 \mathrm{~m}$ $(\mathrm{M}=1.42, \mathrm{SD}=0.19)$ and $1.20 \mathrm{~m}(\mathrm{M}=1.64, \mathrm{SD}=0.13)$ than the narrower widths, see Table 4 . The mean velocity at a width of $1.35 \mathrm{~m}$ was not significantly higher than the velocity at $1.20 \mathrm{~m}$ width.

Table 4. Movement Speeds; Average Values and Standard Deviations.

\begin{tabular}{lllll}
\hline Scenario & Width $[\mathrm{m}]$ & $\begin{array}{l}\text { Number of values in } \\
\text { the random samples }\end{array}$ & $\begin{array}{l}\text { Mean Velocity } \\
{[\mathrm{m} / \mathrm{s}]}\end{array}$ & Standard Deviation \\
\hline 1 & 0.60 & 98 & 1.32 & 0.13 \\
2 & 0.75 & 98 & 1.31 & 0.13 \\
3 & 0.90 & 98 & 1.32 & 0.14 \\
4 & 1.05 & 98 & 1.42 & 0.19 \\
5 & 1.20 & 98 & 1.64 & 0.13 \\
6 & 1.35 & 98 & 1.64 & 0.15 \\
\hline
\end{tabular}

The density varied between 0.8 and $1.2 \mathrm{p} / \mathrm{m}^{2}$. The average density was $0.90 \mathrm{p} / \mathrm{m}^{2}$ for the widths between 0.9 and 1.2 meters, see Fig. 4 (b).

The dynamic flow rate increases linearly with an increase of the width of the walkway, see Fig. 4 (c) and Eq. 5. A simple linear regression was performed in order to determine if the width of the walkway can predict the dynamic flow rate outcome. The result suggests that the predictor (width) explains $96 \%$ of the dynamic flow variance, $R^{2}=.96, F(1,26)=666.78, p<.001$ and that dynamic flow rate is significantly predicted by the width of the walkway, $\mathrm{b}=1.27, \mathrm{t}(26)=25.82, \mathrm{p}<.001$. The $\alpha$ constant in Eq. 5 is not commented, since it is just an outcome of the regression analysis. The $\beta$ value, on the other hand, shows, with a high level of accuracy, how the dynamic flow increases with increasing walkway width. Along with the solid line of regression in Fig. 4 (c), a confidence interval (inner red dotted), and a (outer red dotted) prediction interval to the measured values are presented, both with a level of $95 \%$ certainty. The prediction interval shows the area in which new measurements is expected to end up.

$$
\text { Dynamic Flow }=1,27 \cdot \text { Width }+0,07
$$

The specific flow lies at an approximately constant level between 0.90-1.35 metre widths, but increases for the narrower widths, see Fig. 4 (d).

As can be seen in Fig. 5 (a) and (b), the results from the experiment is similar to values observed in previous work. The data from this study and previous research are represented with dots and lines respectively. Togawa [19] and London Transport Board (LTB) [20] are studies of subway commuters and Fruin's study [21] is based on observations of train and bus commuters. Kendik's data is gathered from various activities [22].

The questionnaire responses indicate that at a width of 0.60 metres, $17(36 \%)$ participants experienced some amount of uncertainty due to the width. At a width of 0.90 metres, 45 (94\%) participants claimed that they did not feel any uncertainty at all due to the width, see Table 5.

Responses regarding walkway height indicate that an increasing width of the walkway reduces the discomfort of height. As shown in Table 6, at a width of 0.75 metres, 27 (56\%) respondents claimed that height was not unpleasant at all. At 0.90 metres width, 40 (83\%) participants did not experience any discomfort. At the maximum width, 1.35 metres, 46 (98\%) respondents experienced no discomfort due to the height. 
(a)

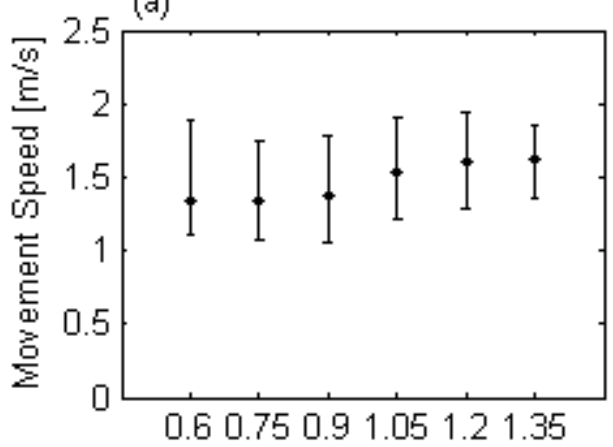

Width of the walkway $[\mathrm{m}]$ (c)

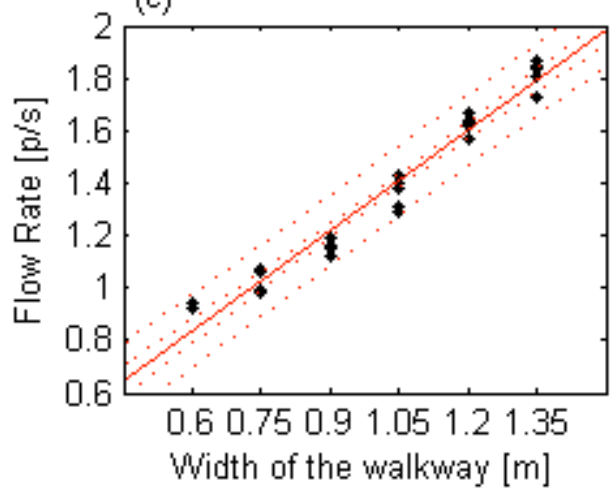

(b)

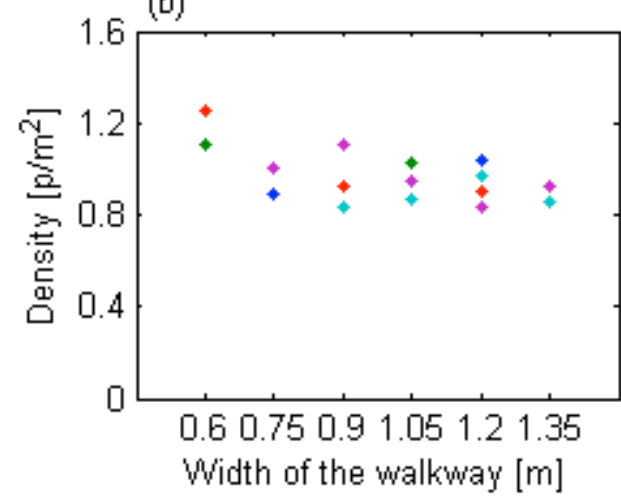

(d)

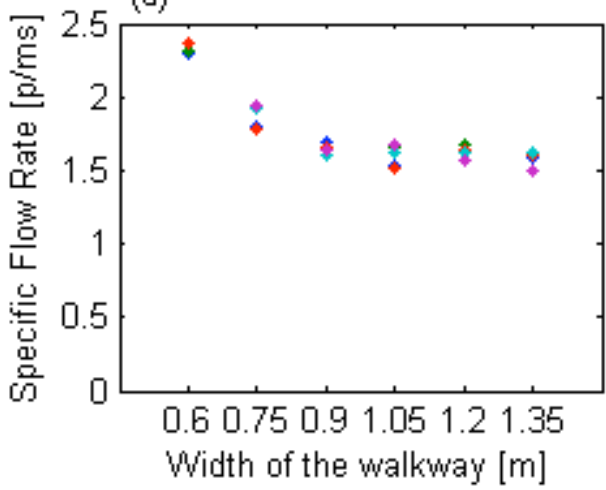

Fig. 4. Evacuation behavior; (a) Movement speed, (b) Density, (c) Dynamic Flow Rate, (d) Specific Flow Rate.
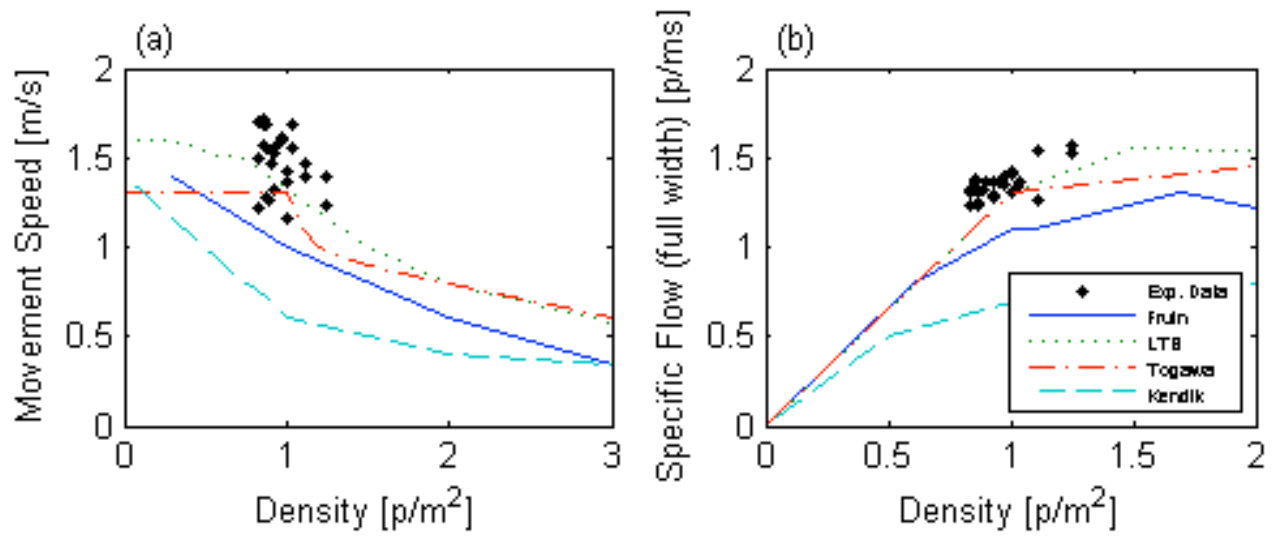

Fig. 5 (a) Comparison of Movement Speed, (b) Comparison of Specific Flow Rates. 
Table 5. Responses regarding the statement of discomfort due to width.

\begin{tabular}{lcccccc}
\hline Response options & \multicolumn{5}{c}{ Number of participants (Percentage of responses) } \\
\hline & Scenario 1 & Scenario 2 & Scenario 3 & Scenario 4 & Scenario 5 & Scenario 6 \\
\cline { 2 - 7 } Strongly Agree & $1(2 \%)$ & $0(0 \%)$ & $0(0 \%)$ & $0(0 \%)$ & $0(0 \%)$ & $0(0 \%)$ \\
Width 0.60 m & Width 0.75 m & Width 0.90 m & Width $1.05 \mathrm{~m}$ & Width $1.20 \mathrm{~m}$ & Width $1.35 \mathrm{~m}$ \\
\hline Disagree & $11(24 \%)$ & $0(0 \%)$ & $0(0 \%)$ & $0(0 \%)$ & $0(0 \%)$ & $0(0 \%)$ \\
Strongly Disagree & $18(38 \%)$ & $14(29 \%)$ & $3(6 \%)$ & $1(2 \%)$ & $2(4 \%)$ & $0(0 \%)$ \\
\hline
\end{tabular}

Table 6. Responses regarding the statement of discomfort due to height.

\begin{tabular}{lcccccc}
\hline Response options & \multicolumn{5}{c}{ Number of participants (Percentage of responses) } \\
\hline \multirow{2}{*}{ Strongly Agree } & Scenario 1 & Scenario 2 & Scenario 3 & Scenario 4 & Scenario 5 & Scenario 6 \\
\cline { 2 - 6 } Width 0.60 m & Width 0.75 m & Width 0.90 m & Width $1.05 \mathrm{~m}$ & Width $1.20 \mathrm{~m}$ & Width $1.35 \mathrm{~m}$ \\
\hline Agree & $12(25 \%)$ & $0(0 \%)$ & $0(0 \%)$ & $0(0 \%)$ & $0(0 \%)$ & $0(0 \%)$ \\
Disagree & $5(11 \%)$ & $1(2 \%)$ & $0(0 \%)$ & $0(0 \%)$ & $1(2 \%)$ \\
Strongly Disagree & $20(42 \%)$ & $27(56 \%)$ & $40(83 \%)$ & $44(92 \%)$ & $45(96 \%)$ & $46(98 \%)$ \\
\hline
\end{tabular}

\section{Part 2 - Test of Evacuation Aids}

The questionnaire results suggest that both the handrail and the raised edge are perceived as facilitating and safety enhancing, even though the evacuation aids were not used by the majority of the participants.

A compilation of the responses show that 11 (52\%) participants experienced the handrail to be safetyenhancing, while $8(38 \%)$ did not experience any difference from not having it. Regarding the tactile edge marker, 13 (62\%) participants stated that they felt safer, while 5 (24\%) did not experience any difference. Movement speed in scenarios $7-9$ was constant at $1.5 \mathrm{~m} / \mathrm{s}$. The flow rate was constant at $1.2 \mathrm{p} / \mathrm{s}$ and the specific flow was constant at $1.7 \mathrm{p} / \mathrm{ms}$. Density decreased slightly, from $0.9 \mathrm{p} / \mathrm{m}^{2}$ in scenario 7 to 0.8 in scenarios 8 and 9 .

\section{DISCUSSION}

The study aimed to investigate the relative effect of walkway design on evacuation behaviour. The results were not studied as absolute values for a heterogeneous population. Instead the main goal has been to quantify the parameter dependencies as relative relationships, e.g., compare peoples' perception of safety with and witout handrails. Despite the specific characteristics of the participants, i.e., young adults, and the fact that the study included only a homogenious population, the results are similar to values presented in previous studies. This is an indication that the results could be extrapolated for a direct usage in future costbenefit analyses of walkway design.

The questionnaire responses demonstrate a higher perception of safety with increasing walkway width. The participants' perceived safety increases rapidly from a walkway width of 0.60 to a width of 0.90 metres. Thereafter the perception of safety remains constant for the wider widths. Thus, the questionnaire responses give a clear indication that the width of around 0.90 metres is the narrowest walkway width on which most evacuees would feel safe.

The dynamic flow rate correlates linearly with the width of the walkway. The strong correlation suggests that the equation is fully applicable for flow calculations for all included walkway widths, i.e., from 0.60 to 1.35 metres. With a wider walkway, a higher dynamic flow rate was observed. The regression equation could therefore be used in the cost-benefit analysis when designing new tunnel walkways. The flow on the 
width of the walkway should also be matched to the flow determined by the train exits, in order to design the most cost-effective solution, when building a new walkway.

Evacuation aids were shown to improve the sense of safety on the walkway. A handrail along the tunnel wall is considered to be a good supplement. The handrail provides an additional sense of safety. The questionnaire shows that a majority of participants' thought that the handrail was very helpful, although the participants that used it just rested his or her hand on top of the handrail as an extra security. Also, the tactile edge marker was considered to be a good feature, with regards to measuring the perceived safety level.

The movement speed is fairly constant on the widths ranging between $0.60-0.90$ metres. The speed then increases significantly at the width of 1.05 metres, to increase again at 1.20 metres. The minimum walkway width recommended, in aspect of the movement speed, is thus around 1.05 metres.

The results of this study are consistent with those of Togawa, LTB and Fruin. Togawa and LTB are both studies of subway commuters and Fruin's study is based on observations of train and bus commuters. The participants in this experiment moved at relatively high speeds at high densities. The relationship between walking speed and density is consistent with the movement pattern of subway commuters. What separates a commuter in an emergency situation from the case in which the commuter is walking in a subway station in ordinary cases, is that the environment in an emergency situation is unknown. This could lead to a lower speed with the same person density. In this experiment, however, there was only one path to choose and the subjects had prior instruction where they should go. This may explain why no observations were made of the expected reduced speeds for an emergency situation. Another reason may be that the population in these experiments consisted of young adults and do not reflect a typical commuter population. Furthermore, knowing that they were being observed, may have influenced the participants to move more quickly than would be expected in real life. The experiment data received are results within orderly evacuation scenarios. If the commuters in a real evacuation are stressed, e.g. by intense radiation, a slightly different evacuation behavior may occur. Future research should focus on validating the results by measuring movement behavior in real evacuation situations, e.g. using video recordings from real events.

The selection of the participants is not consistent with an actual population of train and subway commuters in the sense that the participants' average age was low, no person had any noticeable disabilities, no children or elderly people participated, and the group consisted of a male majority. This selection bias should be considered when using the results as absolute values. Despite the homogenous population used, the walking speeds in this experiment are similar to values presented in previous work. This is an indication that this relative study could be extrapolated to use as an absolute study (with the derived values).

Another potential limitation is that the raised walkway used in the experiment was relatively short. People will pressumably walk faster initially and then slow down as they become tired. This would then lead to higher movement speeds in the experiment than in real-life tunnel evacuation situations involving longer distances. In a recent experiment in a smoke filled tunnel environment, it was not possible to detect a reduction of walking speed for the first couple of hundred metres of evacuation [23]. However, it can not be ruled out that there may be a difference for longer distances. This is consequently a relevant limitation to keep in mind when using the data from the present study.

The specific flow rate is constant for the larger widths. The flow decreases substantially between the widths of 0.6 and 0.75 metres, then decreases slightly for the width 0.90 meters. This may be explained by the movements of the participants. With a narrow walkway, the evacuees cannot sway as much as when walking in normal conditions. Paul's model with the effective width may not be valid for widths narrower than 0.90 metres. The same result is seen in the density. The density is fairly constant for all widths except for the width of 0.60 metres. At this width, the density is higher. This could also be explained by the change in movement pattern.

The experiments were performed in a non-authentic environment. The people in the experiments saw that there were no dangers ahead in the tunnel. No train was approaching and there was no rail. This probably contributed to a decreased respect for the edge of the walkway. The wall built on the platform was made of wood and was reasonably clean, which may have contributed to the fact that people may have walked closer to the wall than what they would have done if the wall had been more uneven and dirty. According to Pauls, the flow is $4 \%$ less for a rough tunnel wall than for a smooth wall. To use the flow results from 
this study in a tunnel with uneven walls, the flow rate should thus be multiplied by a factor of 0.96 . The subjects in the experiments wore neither coats nor bags, although evacuating persons from a train can be expected to carry these items, This also affects the results in the sense that flow rates in this study may be as much as $6-10 \%$ higher than what can be expected in a real emergency [17].

The width of the walkway was increased between each scenario. This may have introduced a systematic error in the results as the participants got used to the height and the edge of the walkway. This has possibly also affected the participants' movement speed. In the questionnaire responses, a hint of this is seen as $98 \%$ of the participants stated that they did not experience the height as troublesome on the wide walkway. This could have been avoided by varying the width of the walkway back and forth, but due to safety reasons the wall was moved from the narrowest to wider widths.

\section{CONCLUSIONS}

The results derived from the experiment show that the dynamic flow rate increases linearly with increasing walkway width. Movement velocity was observed to remain fairly constant, despise changes in walkway width, as did the density and the specific flow rate for the larger widths. Considering both questionnaires and movement speed, the recommended minimum width of the walkway is in the range of one metre to provide a sense of safety among the evacuating commuters. Handrail and tactile edge markers are regarded to be good supplements for evacuation. The flow on the width of the walkway should also be matched to the flow determined by the train's exits, in order to design the most cost-effective solution, when building a new tunnel. In order to use this data when designing tunnel walkways, care shall be taken since the study aimed to derive relative values in an orderly evacuation scenario.

\section{ETHICAL CONSIDERATIONS}

Ethical principles regarding participants in experiments were followed according to the Swedish ethics act [15]. The participants signed their consent after being informed about the experiment. They were told that their participation was voluntary and that they could abort their participation anytime. Furthermore, they learned that they would remain anonymous; both regarding the video recordings and the questionnaires.

In order to minimize the risk of accidents during the experiments, a what if-analysis was performed. The safety measures introduced based on the analysis included controlling the rig setting, removing obstacles from the lab hall and engaging a care manager to overview the experiments.

\section{ACKNOWLEDGEMENTS}

The authors would like to express their appreciation to the Danish Institute of Fire and Security Technology (DBI) and Lund University (LTH) for the opportunity to write this paper. The authors are also indebted to the METRO and KES $\varnothing$ projects for funding the experiment.

\section{REFERENCES}

[1] Larsson, S. (2004) Tunnelolyckan i Kaprun 2000 [Tunnel Accident in Kaprun 2000]. Stockholm: Försvarshögskolan.

[2] Schupfer, H. (2001) Fire disaster in the tunnel of the Kitzsteinhorn funicular in Kaprun on 11 Nov. 2000. Paper presented at the fourth International Conference on Safety in Road and Rail tunnels, Madrid, Spain.

[3] Fennell, D. (1988). Investigation into the King's Cross Underground Fire. London: The Department of Transport.

[4] Rohlen, P., \& Wahlström, B. (1996) Tunnelbaneolyckan i Baku, Azerbaijan 28 oktober 1995 [The Subway Accident in Baku, Azerbaijan, 28 October 1995]. Karlstad: Statens räddningsverk.

[5] Fridolf, K., Nilsson, D., \& Frantzich, H. (2011) Fire Evacuation in Underground Transportation Systems: A Review of Accidents and Empirical Research. Fire Technology, 1-25.

[6] Burnett, J. (1984). Fire Safety Concerns for Rail Rapid Transit Systems. Fire Safety Journal, 8(1), 3-7. 
[7] Fermaud, C., Jenne, P., \& Müller, W. (1995). Fire in a Commuter Train - Rescue Procedures as Perceived by Passengers. Paper presented at the second International Conference on Safety in Road and Rail Tunnels, Granada, Spain.

[8] Fridolf, K., Nilsson, D., \& Frantzich H. (2012) Train Evacuation Inside a Tunnel: An Interview Study with Senior Citizens and People with Disabilities, Proceedings of the 5th International Symposium on Human Behaviour in Fire, Cambridge, UK, 346-357.

[9] Oswald, M., Kirchberger, H., Lebeda, C. (2008) Evacuation of a High Floor Metro Train in a Tunnel Situation: Experimental Findings, $4^{\text {th }}$ International Conference on Pedestrian and Evacuation Dynamics - PED 2008, pp. 67-81.

[10] US Department of Transportation (2012) Findings on Underground Transportation Systems. retrieved from http://international.fhwa.dot.gov/uts/uts_eu06_02.cfm (10th June, 2012)

[11] Trafikverket (2011) Trafikverkets tekniska krav Tunnel [The Swedish Transport Administration's Technical Requirements for Tunnels] (TRV publ nr 2011:087), Borlänge: Trafikverket.

[12] Council Directive 2008/163/EC of 20 December 2007 concerning the technical specification of interoperability relating to 'safety in railway tunnels' in the trans-European conventional and highspeed rail system (2007).

[13] Ahlfont, J. and Vermina Lundström, F. (2012) Tunnelutrymning: Effekten av gångbanans bredd på förflyttningshastigheten vid utrymning $i$ en spårtunnel. [Tunnel Evacuation: An investigation into width a speed determinant in the evacuation of railway tunnels via the use of walkways] Lund: Brandteknik och riskhanteing, LTH

[14] Research Methods Knowledge Base (2012) Likert Scaling. Retrieved from http://www.socialresearchmethods.net/kb/scallik.php (15th May, 2013)

[15] SFS 2003:460 - Lag (2003:460) om etikprövning av forskning som avser människor [The act concerning the ethical review of research involving humans], 2003.

[16] Nelson, H., Mowrer, F. (2002). Emergency Movement.|: DiNenno, Philip J. (red.) (2002). SFPE handbook of fire protection engineering. 3. ed. Quincy, Mass.: National Fire Protection Ass.

[17] Frantzich H. (2000). Utrymning av tunnelbanetåg: experimentell utvärdering av möligheten att utrymma i spårtunnel : [Evacuation from subway trains: An experimental evaluation of the possibility to evacuate in a rail tunnel] Karlstad: Räddningsverket

[18] Blom, G., Holmquist, B. (1998) Statistikteori med tillämpningar [Statistic Theory and Applications]. Studentlitteratur, Lund.

[19] Togawa K. (1955). Study on fire escapes on the observation of multitude currents. Tokyo. Building Research Institute, Ministry of Construction.

[20] LTB. (1958). London Transport Board. Second report of the operational research team on the capacity of footways. Report 95. London 1958

[21] Fruin J. J. (1971). Pedestrian planning and design. Metropolitan association of urban designers and environmental inc. New York

[22] Kendik E. (1986). Designing escape routes in buildings, in Fire Technology Volume 22, No 4.

[23] Fridolf, K., Ronchi, E., Nilsson, D., \& Frantzich H. (2013) Movement speeds and exit choice in smoke-filled rail tunnels, Fire Safety Journal, 59, 8-21. 